\title{
Customer Behavior in Electronic Commerce: A Bayesian Approach
}

\section{Silvana Dakduk ${ }^{1}$, Enrique ter Horst ${ }^{2}$, Zuleyma Santalla ${ }^{3}$, German Molina ${ }^{4}$ and José Malavé 5}

\footnotetext{
${ }^{1}$ Colegio de Estudios Superiores de Administración - CESA, Departament of Marketing, Bogotá, Colombia, silvana.dakduk@cesa.edu.co

${ }^{2}$ Colegio de Estudios Superiores de Administración - CESA, Departament of Finance, Bogotá, Colombia, enrique.terhorst@cesa.edu.co

${ }^{3}$ Universidad Católica Andrés Bello - UCAB, Departament of Psychology, Caracas, Venezuela, zsantall@ucab.edu.ve

${ }^{4}$ Idalion Capital US LP, Quantitative Trading Group, FL, USA, german@alumni.duke.edu

${ }^{5}$ Instituto de Estudios Superiores de Administración - IESA, Department of Management and Leadership, Caracas, Venezuela, jmalave@iesa.edu.ve
}

Received 10 June 2016; received in revised form 16 Novemeber 2016; accepted 15 December 2016

\begin{abstract}
Online shopping has increasingly replaced traditional retail shopping, as a large number of consumers have adopted it on a global scale. However, while it is well established in developed countries, e-commerce is still at an early stage in emerging markets, hence there is a need to unveil which factors contributes to its adoption. The main objective of this study is to integrate the theory of planned behavior, the theory of reasoned action, and the technology acceptance model using a Bayesian approach to determine the key predictors of online purchase intention among internet users in Colombia. The results demonstrate the pertinence of the theory of reasoned action and technology acceptance model, models to explain online purchase intention, confirming that the intention to purchase online is mostly determined by the attitudes to e-commerce which, in turn, are explained by perceived usefulness, perceived ease of use, and the subjective norm related to online shopping.
\end{abstract}

Keywords: Intention, Attitude, Internet, E-purchase, E-commerce, E-customers, Bayesian, MCMC 


\section{Introduction}

The emergence of the Internet has prompted enormous changes in consumer behavior [19]. Increasing numbers of consumers are using electronic commerce (e-commerce) to shop for products and services [38]. However, despite the accelerated spread of e-commerce, there are significant differences in growth, penetration and adoption of the Internet as a viable alternative to traditional shopping at a global level. According to the Global Retail e-commerce index, the United States, China, United Kingdom, Japan and Germany have an online market size over $60 \%$, in contrast with emerging economies in Latin American countries included in the studies (Venezuela, Chile, Argentina, Brazil and Mexico) with an online market size of $7,9 \%$. Never the less, despite to its small size, the study highlights a growth potential of $50 \%$ which cannot be ignored [15].

In relation to the above mentioned Latin America accounts for $10.5 \%$ of the world's Internet users [39]. It is considered a promising market [30], since its Internet penetration (49\%) surpasses the global rate (38\%), and shows an accelerated and sustained growth in almost all of its 20 countries [39], [40].

In the Latin American context, Colombia occupies the fourth place in Internet penetration (61.6\%), and shows one of the most remarkable growth levels of online activities in the past few years [39], [40]. Colombia has jumped to the third place of Internet usage in the region (9.6\%), with the second highest rate of Internet access, reflecting a greater growth in digital behavior at a regional and global level [8], [39], [40]. However, e-commerce in Colombia is still in its infancy. Although more than $60 \%$ of Colombian Internet users utilize the web for browsing, consulting, and evaluating products and service offers, only $20 \%$ of them actually complete transactions [29], [55]. In 2013, total sales for online purchases in Colombia reached $\$ 8,283,000$ [18]. In 2014 , sales grew $45 \%$ over those of 2013, which means that more than two million Colombians purchase online with an average purchasing expenditure of USD $\$ 146$ [29].

E-commerce sales in Colombia are projected to grow in the upcoming years due to the following conditions that increase the intention and execution of online transactions: (a) an increase in digital literacy, (b) a decrease of Internet costs, (c) an expansion of Internet service suppliers, (d) an expansion of digital and non-digital goods offered online, (e) an increase of mobile device penetration, ( $f$ ) an increase of penetration in banking services, and $(\mathrm{g})$ an increase and diversification of payment methods. Given the relevance of e-commerce growth in Colombia and the evidence suggesting that online purchase intention is the best predictor of online shopping behavior [78], the primary objective of the present study is to determine which variables influence online purchase intention in Colombia's expanding e-commerce industry.

The proposed theoretical framework is based on the integration of the theory of reasoned action (TRA), the theory of planned behavior (TPB), and the technology acceptance model (TAM). While it is certain that in recent years, a prolific and versatile empirical research on the factors influencing customer behavior in e-commerce has been published using this theoretical framework; most of it has focused on developed economies [59], showing that research evidence is still scarce in Latin American countries.

Research in the adoption of technology, especially related to e-commerce, is still in an early phase of theoretical development [74]. Thus, the meta-analysis conducted on 109 studies about the factors affecting the adoption of ecommerce did not focus on Latin American countries [38]. This was also observed in the 2015 literature review of 174 studies based on the Unified Theory of Acceptance and Use of Technology. Finally, in a meta-analysis study which focused on mobile banking, of the 57 studies included in the review, none had been conducted in Latin America [11]. Although the predictive power of the model has been extensively evaluated, conducting research in the Latin American geographical and geopolitical context is particularly important since some authors suggest different results and influences of those variables depending on the cultural context [4], [33].

In addition, the present study makes a methodological contribution since most of the studies reported in the literature have been done by mainly using structural equation modeling (SEM) [1], [38]. The present study uses an innovative and less used Bayesian approach that offers several advantages in respect to the traditional methods, and more adaptability to Latin American studies (limited reliance on large sample size, simplicity for handling missing data, ability to incorporate prior knowledge, among others) using technology acceptance model (TAM) [1], [5]. Academics and practitioners interested in the growing Business to consumer (B2C) Internet market in emerging economies will benefit from the results of this research, allowing for further understanding of the factors influencing e-commerce. 


\section{Literature Review and Research Hypotheses}

The acceptance of a new technology is an important condition to predict the intention, use and satisfaction of the latter technology. The spread of technology and its impact on users have contributed to the development of theories and models that seek to explain how users relate to technology. The most discussed theories in this area are the theory of reasoned action (TRA) [6], [27], the theory of planned behavior (TPB) and, the technology acceptance model (TAM) which are explained in the next two sections.

\subsection{The Theories of Planned Behavior and Reasoned Action}

In 1991 the theory of planned behavior (TPB) was developed for overcoming limitations of the theory of reasoned action (TRA) [6], [44]. Both theories share the premise that behavior is under the individual's will and control, and that its immediate determinant is not the attitude, but the intention of executing a given action. Intentions "are indications of how hard people are willing to try, of how much effort they are planning to exert, in order to perform the behavior" [6] p. 181. Therefore both theories are intended for probabilistic prediction and understanding of determinants of behavior: a prediction of a behavior's probability of occurrence is obtained by measuring the individual's intention of performing such a behavior. The original TRA's formulation [27] stated that behavioral intention $(\mathrm{BI})$ is a function of two determinants. First, the attitude towards a behavior is a positive or negative evaluation of the performance, determined by the individual's beliefs regarding the consequences (positive or negative); that is, the individual's expected probability that, by executing behavior $x$, the result will be consequence $i$, and his/her evaluation of such consequence. Second, the subjective norm, which refers to the perceived social pressure for executing the behavior or not, being a function of the individual's expectations that socially relevant individuals or groups consider he/she should perform behavior $x$, and his/her motivation to fulfill such expectations [27] (Figure 1).

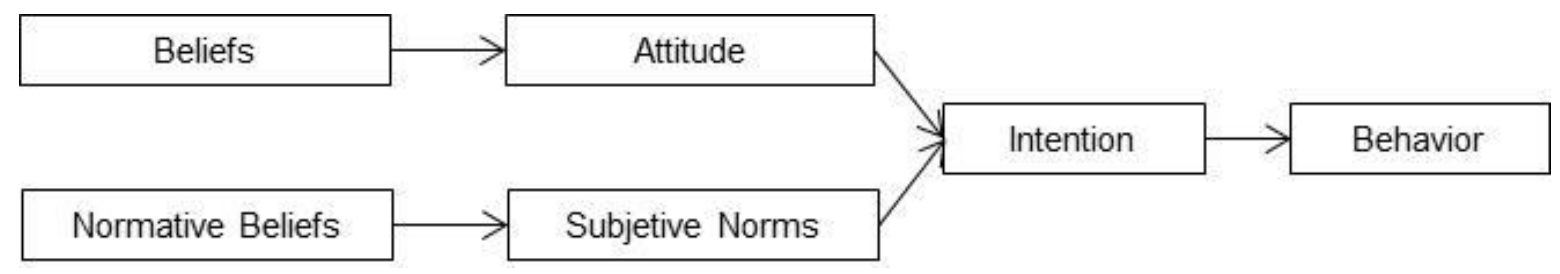

Figure 1: Theory of reasoned action [27]

However, the authors recognized that the proposed relationship intention-behavior is not direct or immediate because there are mediating factors such as (a) the individual's experience with the attitudinal object, (b) the intention's stability through time, (c) the presence of other people, and (d) the abilities required to perform the behavior [6]. Based upon these considerations, [5] took into account the limitations, perceived or actual, the individual face in order to perform the behavior, and introduced a new variable: perceived behavioral control (PBC). With this new variable, the TPB was postulated in a way so that, PBC has an indirect effect on behavior and a direct effect on behavioral intention (Figure 2). [16], [26], [19], [49], [54], [70].

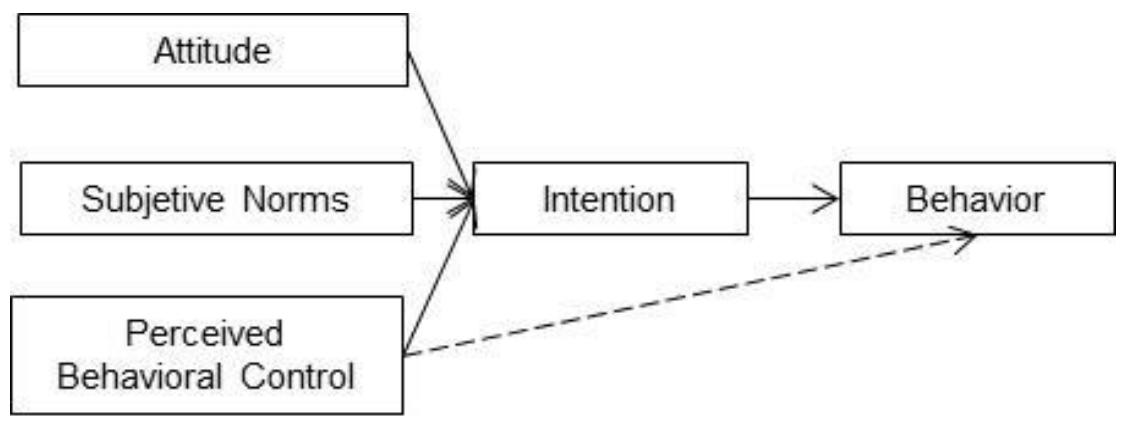

Figure 2. Theory of planned behavior [18]

PBC denotes the ease or difficulty perceived by the individual for performing a behavior. PBC is determined by (a) the individual's beliefs that he/she has access to what is needed to perform the behavior; and (b) the individual's perceived power over the factors contributing to the behavior's performance [18]. TRA and TPB have been applied and examined in different areas of psychology and related disciplines. In the field of consumer behavior these theories have been used for explaining the acquisition and change of attitudes toward categories, products, and brands, as well as attitudes and intentions related to buying, re-buying, use, and re-use of products and services [4], 
[5], [19], [20], [21], [26], [49], [54], [70]. In meta-analytic studies it has confirmed the predictive usefulness of TRA in the study of consumer behavior, confirming a positive relationship between the intention and the actual performance of a behavior, and positive and significant correlation between attitude and subjective norm with the intention to perform a behavior [71].

Both TRA and TPB have also been used in studying consumer behavior in virtual settings, showing their effectiveness in predicting intention and performance of purchasing behavior and electronic commerce adoption. For instance, in a study that analyzes the factors that influence online purchase intention in a sample of 260 Iranians, support was found for all the relations proposed by TPB, as well as the role played by friends on subjective norms and that of perceived credibility over attitude toward online shopping [60].

Within this line of research, and built upon a sample of users in Medellin (Colombia), it was found that both the attitude towards e-commerce as the subjective norm and perceived behavioral control significantly predict the intent to use e- commerce [73]. Additionally, comparing the predictive power of TRA and TPB in predicting e-commerce adoption intentions among 212 small and medium sized business managers/owners in Chile it was found that attitude and subjective norm significantly predicted behavioral intention, and that there was no statistically significant difference between the models' goodness of fit [59]. However, the authors found a slightly better performance of TRA which accounted for the same amount of variance as TPB using a smaller number of parameters; in this particular sample, PBC did not predict the intention of adopting e-commerce significantly [59]. This finding does not deny TPB's usefulness. It can be expected that the relative importance of attitude, subjective norm, and perceived behavioral control, in predicting intention, vary according to the behavior under study and the population characteristics [4]. The actual prediction could require introducing a specific combination of these variables, or even beliefs particularly related to the attitudinal object [4]. This is the reason why a theoretical integration of TRA and TPB is frequently observed, combined with the technology acceptance model (TAM) or others models such as the Unified Theory of Acceptance and Use of Technology (UTAUT) in predicting behavioral intentions in technological contexts.

In this sense, in an extension of UTAUT for Palestine e-commerce it was confirmed that the attitude toward shopping for products and services via online and social influence (related to the subjective norm construct) has a significant and positive influence on the intention to shop online shopping. However, the influence of facilitative conditions (related to PBC construct) on intention of buying online was found to be non-significant [58]. Finally, in a metaanalytic review about e-shopping acceptance, in which the authors tested the extended TRA and extended TAM models for e-shopping, it was confirmed that both the attitude toward shopping online and the social influence significantly predicted the intention to shop online [38].

In accordance with the TPB, TRA and the empirical evidence from [11], [34], [38], [45], [52], [59], [60], [71], [73] we proposed the following hypotheses:

H1: Attitude has a direct positive influence on intention to shop online.

H2: Subjective norm has a direct positive influence on intention to shop online.

H3: Perceived behavioral control has a direct positive influence on intention to shop online.

\subsection{The Technology Acceptance Model}

Based upon TRA, Davis [24], developed the technology acceptance model (TAM) to explain technology adoption of technologies [23], [25]. TAM is one of the most important and successful theories for understanding technology acceptance [35], [46], focus on the use of technology innovations made it more appropriate than other approaches in analyzing this kind of behavior [34], [36], [46], [67]

TAM has become a useful model for explaining online purchasing and has been successfully adapted and extended to e-commerce [38]. The model stems from the analysis of external factors on individual beliefs, attitudes, as conceptualized by [5]. Davis specified two beliefs that influence the acceptance of IT innovations: (a) perceived usefulness (PU) and (b) perceived ease of use (PEOU) [24], [25]. PU refers to the perception of a user about the subjective probability that the use of technology will help increase her/his performance or have a better performance when using a specific information system. Alternatively, PEOU refers to the individual's subjective appreciation that using a particular technology requires or involves the least possible effort [24], [25].

According with TAM, PEOU has a direct effect on attitude and an indirect effect on intention, while PU has direct effects on both attitude and intention, and only intention has a direct effect on the use of technology (Figure 3) [23][25]. 


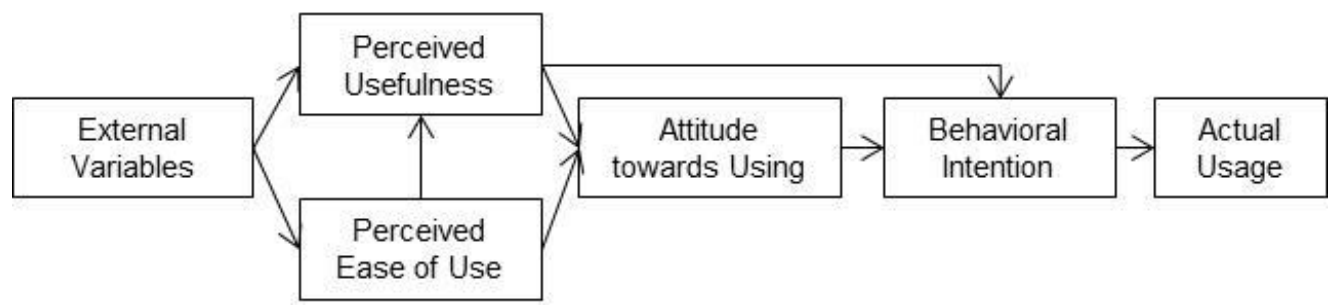

Figure 3. Technology Acceptance Model [24]

TAM's [21] success and popularity built upon, among others, two key reasons: (a) it is simple and easy to understand [43], and (b) the measurement scales used are reliable, adapted to the context of information technology realm, and allow comparison of results between different information systems [48]. A key differentiating feature of TAM, with respect to TPB, is the exclusion of subjective norm and perceived behavioral control as determinants of behavioral intention, since the effect of reference groups is considered to be exerted indirectly through attitude [43] , [50]. However, based upon the contributions in [42], [80] social influence is introduced into TAM [79], [50]. Additionally, within TAM, beliefs referred to the attitudinal object are replaced by specific beliefs on technological systems (PU and PEOU). The main limitation attributed to TAM is the general character of the information it provides, since it exclusively considers perceived usefulness and ease of use [52], [75]. TPB and TRA are superior, in this regard, because they take into account the influence of specific beliefs instead of influencing attitudes, and the effects of reference groups and other factors that the individual could consider obstacles to their behavior [52].

In this sense, the perceived usefulness and ease of use could be affected by different variables such as user experience, satisfaction, innovation disposition, and motivation [25]. Thus, research in this field has evolved towards understanding the influence of external factors on perceived usefulness and ease of use [38], such as: (a) technological systems' features[2], [21], [26], [53]; (b) previous experience [2], [28], [34], [35]; (c) perceived fun in the process [77]; (d) innovation disposition [73]; and (e) intrinsic motivation, such as self-efficacy [13], [14], [17], [20], [21].

In a meta-analysis conducted with 88 empirical studies to evaluate the predictive power of TAM, it was found that PU and PEOU significantly predict behavioral intention, explaining $50 \%$ of the variance of behavioral intention, even if the PU was a better predictor of intention that PEOU. Also, it was found that PEOU influences PU positively and significantly. This was confirmed across different contexts of study (internet usage, e-commerce and other technological systems) [43].

Consistent with these results and as formulated in the TAM, in a meta-analysis of 57 empirical research papers on mobile banking acceptance, it was found that the performance expectancy and the effort expectancy (construct considered by the authors as related to PU and PEOU) significantly and positively influenced the attitude. In addition, the attitude and the performance expectancy kept a direct, positive and statistically significant effect toward the intention to use mobile banking. Finally, the relationship between effort and performance expectancy was also confirmed [11].

Numerous studies used TAM as their main theory for investigating variables influencing e-commerce adoption and use. For instance, in a study aimed at evaluating the usefulness of TAM in consumer acceptance of e-commerce, it was found that the perceived usefulness of the Web interface was positively related to the consumer intention to complete the transaction, and that PEOU kept a significant and positive relationship with the intention to carry it out in the general consumer population, but not within a sample of students. Likewise, the perceived ease of use was positively related to perceived usefulness of a Web interface [65]. Similar results were found with a sample of 213 experienced online shoppers from the United States, confirming that both PU and PEOU positively affect intentions to buy with the last e-vendor from which they purchased, and that PEOU positively affects PU of a B2C web site [31].

Additionally, in an analysis of perceptions that induce Spanish consumers to buy over the Internet, the authors considered all the variables proposed in TAM, and added perceived self-efficacy in using Internet preceding PEOU and PU, as well as factors related to previous experience with the Internet (acceptance, frequency of use, and satisfaction) as predictors of perceived self-efficacy [34]. The purpose of this study was to examine the influence of those variables on the intention of online purchasing, considering the potential mediating effect of customers' epurchasing experiences. The authors developed a structural equation model to be tested with two samples of frequent Internet users: 580 potential e-customers (who were considering making their first e-purchase) and 225 experienced e-customers (who had made at least one e-purchase and were considering doing so again).

The results showed that PU had a positive effect on the attitude toward e-commerce in both samples, but the effect was greater among experienced e-customers. PEOU did not predict significantly the attitude toward e-commerce, in either sample. In addition and in line with the results found by other authors previously cited, attitude accounted for $67 \%$ of e-purchasing intention variance among potential e-customers, and $65 \%$ among experienced e-customers. On the other hand, in both samples, Internet acceptance exerted a direct positive effect on the perceived satisfaction 
with the Internet, though with a greater effect among potential e-customers. Additionally, Internet acceptance accounted for a significant percentage of the variance of Internet frequency of use, but only in the case of potential ecustomers. In both samples, Internet acceptance and its frequency of use explained the perceived self-efficacy, with a higher coefficient in the case of experienced e-customers. However, satisfaction with using the Internet did not predict significantly perceived self-efficacy of neither potential nor experienced e-customers. In both samples, perceived self-efficacy, in turn, influenced perceived usefulness and ease of use of e-commerce, though with a greater effect on perceived usefulness among experienced e-customers.

In the same line of research, a study developed with a sample comprising 322 individuals in Saudi Arabia, using all the TAM approach, showed a direct and significant effect of attitude toward online shopping and PU on BI. It also confirmed that the PU and PEOU of online shopping had a positive and significant impact on attitudes toward online shopping, and that consumers' perceived ease of use of online shopping has a positive influence on their perceptions of the usefulness of online shopping [61]. However, attitude did not act as a mediator between eshopping intentions and exogenous variables such as PEOU and PU, and had an insignificant indirect effect on online purchase intention.

The applicability of TAM in predicting the intention to make purchases online by 539 consumers in India was consistent with previous results. PU and PEOU of an e-retailing website positively and significantly influenced the usage of attitude toward an e-shopping website. Likewise, PU and attitude significantly predicted intention to shop online, and PEOU kept a significant and positive relationship with PU [45].

Finally, with a sample of consumers in Medellin (Colombia), the authors tested TAM while adding to the model the variables 'perceived safety' and 'confidence'. Their results showed that PU significantly and positively affected both the attitude towards e-commerce as the intention to use e-commerce, and that there was a significant and positive relationship between PEOU and PU. However, in this study, the authors found no evidence that PEOU significantly predicted attitude nor that attitude was a significant predictor of behavioral intention [74].

As highlighted by literature reviews and recent studies, some researchers have combined TAM, TRA and TPB in an effort to explain online purchasing behavior, or extended versions of these theories including other variables that allow greater accuracy in predicting online purchasing intentions and behaviors.

For instance, [52] combined variables belonging to the three models and included, as external variables: (a) perceived safety; (b) innovativeness; and (c) perceived trust, to study online purchasing intention. According to TPB, results confirmed the direct and significant effects of subjective norm, perceived behavioral control and attitude on the intention of using e-commerce. Regarding the hypotheses derived from TAM, results confirmed the direct effect of PU on attitude and the significant relationship between PEOU y PU, but again the effect of PEOU on attitude was not found significant. Among the additional variables, results showed a direct and significant effect of trust and an indirect and significant effect on perceived security in the intention of using e-commerce.

In line with previous evidence, and with the purpose of unifying some developments derived from TAM to explain online purchasing, [38] evaluated two models: (a) an extended TRA model for e-shopping, which states that PU, PEOU, enjoyment, and perceived risk all relate directly to attitude toward e-shopping, and that attitude, trust, and social influence relate directly to the intention of using e-shopping; and (b) an extended TAM model for e-shopping, which adds that PU, enjoyment, and perceived risk relate directly to behavioral intention and that social influence relate directly to attitude toward e-shopping. In both models, the authors confirmed that PU and PEOU positively and significantly predict attitude towards e-shopping, and in the extended the TAM for e-shopping PU significantly predicted intention. Finally, the authors also confirmed the direct, positive and statistically significant relationship between attitude toward e-shopping and the online purchase intention. The authors found that including attitude toward e-commerce into the original TAM produces a $9 \%$ significant increase of explained variance of intention: from $36 \%$ with the original TAM to $45 \%$ including attitude. When comparing the two models, using structural equation models, the authors found that the extended TAM model for e-shopping explained a higher percentage of variance the intention to purchase online (52\%), compared to the extended TRA model for e-shopping (45.5\%), and showing a better fit.

In accordance with TAM and the empirical evidence from [11], [31], [34], [38], [43], [45], [52], [61], [65], [74] we propose the following hypotheses:

H4: Perceived ease of use of online shopping has a direct positive influence on attitude toward online shopping.

H5: Perceived usefulness has a direct positive influence on behavioral intention toward online shopping.

H6: Perceived usefulness has a direct positive impact on attitudes towards online shopping.

H7: Consumers' perceived ease of use of online shopping has a direct positive influence on their perceptions of the usefulness of online shopping.

Additionally, according to the results reported by [17], [20], [34], in the present study it was expected that:

H8: Consumers' perceived self-efficacy has a direct positive influence on their perceptions of the usefulness of online shopping. 
H9: Consumers' perceived self-efficacy has a direct positive influence on their perceptions of the ease of use of online shopping.

H10: Perceived self-efficacy has a direct influence on perceived behavioral control.

H11: Frequency of internet use has a direct positive influence on perceived self-efficacy.

H12: Acceptance of internet has a direct positive influence on perceived self-efficacy.

H13: Acceptance of the internet by its users has direct positive influence over their frequency of use.

Based upon relevant literature and theoretical foundations, the present study employs an integration and extension of the TRA, TPB, and TAM to explain online shopping intentions in Colombia. The hypotheses model is summarized in Figure 4.

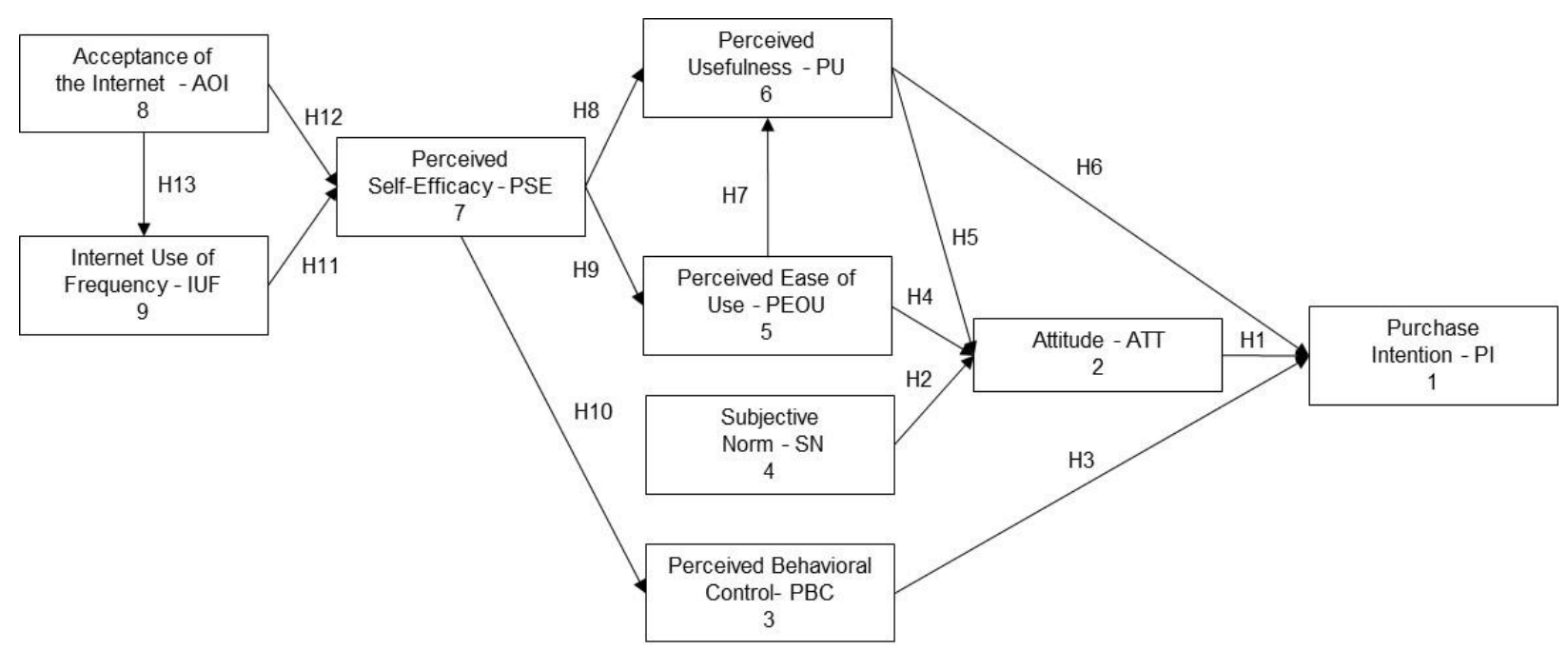

Figure 4. Research Hypotheses Model

\section{Customer Behavior in E-Commerce: Bayesian Approach}

The statistical method most commonly used in studies of behavioral intention, applying TAM, TRA, TRP, as well as integrated or extended versions of these theories, is the structural equation model (SEM) [1]. It provides the estimation strength of all hypothesized relationships between variables in a theoretical model [1], [51]. While the traditional approach involves frequentist estimation of SEMs, this poses significant hurdles for low sample cases, which are likely to be found in Latin America studies (either due to small populations of interest or insufficient funding for larger research undertakings). Our approach allows for a flexible, easy to implement, and robust algorithm. We follow a fully Bayesian approach to the estimation of this model which has multiple advantages: (a) It allows for a more direct interpretation of the latent variables in the model as random variables in a Bayesian fashion, rather than fixed point estimates, (b) It provides a natural and flexible approach to overcoming low samples and missing data, two problems likely to appear in research on emerging economies, and (c) It allows flexible incorporation of prior beliefs on the basis of existing literature (although we chose not to undertake this route, and specified the model with a flat, uninformative prior, the model can easily incorporate this information through the prior specifications).

Our Bayesian approach links the unknown latent variables, assumed observed with error, on the basis of the hypothesized model relationship in Figure 4, and provides a network-with-error structure which allows for simple estimation of the parameters of interest, that is, latent variables and relationships. The interpretability is direct since the posterior distribution of the latent variables account for both the information -and lack thereof- contained in the observed-with-error data, as well as providing distributions, marginal and joint, of the variables of interest, rather than estimators of those. This approach has been proven useful in other sciences in more complex applications, such as traffic engineering [56], where observed-with-error flows provide information about unobserved, latent flows and relationships between those on the basis of an existing relationship network.

More detailed information about the Bayesian method used can be found in the Appendix. The data is assumed to be observed with error, and linked with each other through standard Gaussian links. The unknown, true value of the driving parameters is unobserved, and estimated through this app roach (both point estimates and posterior densities around those, which account for the uncertainty about their values). Hyper parameters are set to be noninformative, to ensure that the driving force of the results comes from the informational content of the data, though the modelling approach allows for prior information. Missing data, though not present in our study, can be easily estimated within this model as additional parameters within the joint distribution. The results are not reliant on central limit theorem properties (they do not provide estimates of an unknown parameter, but the probability distribution of 
the unknown parameters themselves), and are stable even with very low samples. While the model itself is not dissimilar, and definitely comparable to previous approaches, the Bayesian estimation provides a useful edge for challenging sampling environments, and appears to be more suitable for this type of research.

\section{Materials and Methods}

The current investigation is non-experimental, probabilistic and cross-sectional. This scientific research is non experimental because its objective is to explore relationships between variables, in a situation in which, there are manifest variables that already occurred, it is a cross-sectional study because data collection will carried out, in a moment of time and with a single observation and it is probabilistic because we use statistical techniques for the estimation.

Table 1: Measurement scales

\begin{tabular}{|c|c|c|c|}
\hline Scale & Item & Conceptual definition & Reference \\
\hline \multirow{3}{*}{$\begin{array}{l}\text { Acceptance } \\
\text { of the } \\
\text { Internet - } \\
\text { AOI }\end{array}$} & My general opinion about Internet is positive & \multirow{3}{*}{$\begin{array}{l}\text { Previous experience using } \\
\text { Internet }\end{array}$} & \multirow{3}{*}{$\begin{array}{l}{[24],[25],} \\
{[35]}\end{array}$} \\
\hline & Using Internet is easy for me & & \\
\hline & Internet seems useful to me & & \\
\hline $\begin{array}{l}\text { Internet use } \\
\text { frequency - } \\
\text { IUF }\end{array}$ & How often do you use Internet? & Frequency internet use & [35], [62] \\
\hline \multirow{3}{*}{$\begin{array}{l}\text { Perceived } \\
\text { self-efficacy } \\
\text {-PSE }\end{array}$} & I feel capable of using Internet for purchasing products & \multirow{3}{*}{$\begin{array}{l}\text { Individuals' beliefs that } \\
\text { they have the ability and } \\
\text { resources to perform } \\
\text { successfully a task [65], } \\
\text { specifically, an online } \\
\text { buying task }\end{array}$} & \multirow[b]{3}{*}{ [22], [47] } \\
\hline & I feel capable of locating shopping sites on Internet & & \\
\hline & $\begin{array}{l}\text { I feel comfortable searching for information about a product on } \\
\text { Internet }\end{array}$ & & \\
\hline \multirow{6}{*}{$\begin{array}{l}\text { Perceived } \\
\text { usefulness } \\
\text { of e- } \\
\text { commerce - } \\
\text { PU }\end{array}$} & $\begin{array}{l}\text { Using Internet to buy a product would help me to purchase more } \\
\text { efficiently }\end{array}$ & \multirow{6}{*}{$\begin{array}{l}\text { Consumer perception of } \\
\text { Internet as a means for } \\
\text { improving the shopping } \\
\text { performance and } \\
\text { efficiency [61] }\end{array}$} & \multirow{6}{*}{$\begin{array}{l}\text { [24], [35], } \\
{[41],[57],} \\
{[64],[65],} \\
{[75]}\end{array}$} \\
\hline & $\begin{array}{l}\text { Using Internet to buy a product would help me to purchase more } \\
\text { quickly }\end{array}$ & & \\
\hline & $\begin{array}{l}\text { Using Internet to buy a product would be useful to make my } \\
\text { shopping }\end{array}$ & & \\
\hline & Internet makes my shopping efficient & & \\
\hline & Internet is valuable to me & & \\
\hline & Internet is beneficial for purchasing & & \\
\hline \multirow{5}{*}{$\begin{array}{l}\text { Perceived } \\
\text { ease of use } \\
\text { of e- } \\
\text { commerce - } \\
\text { PE }\end{array}$} & Learning to use Internet for shopping was easy for me & \multirow{5}{*}{$\begin{array}{l}\text { Consumer perception that } \\
\text { Internet shopping will } \\
\text { involve minimal effort [71] }\end{array}$} & \multirow{5}{*}{$\begin{array}{l}\text { [24], [35], } \\
\text { [75], [83] }\end{array}$} \\
\hline & Internet would be easy to use for my purchases & & \\
\hline & Using Internet to buy a product does not require a lot of mental effort & & \\
\hline & It is easy to find what I like online & & \\
\hline & Interacting with online stores is easy and intuitive & & \\
\hline \multirow{9}{*}{$\begin{array}{l}\text { Attitude to } \\
\text { e- } \\
\text { commerce - } \\
\text { ATT }\end{array}$} & Buying things or making transactions online is something I like doing & \multirow{9}{*}{$\begin{array}{l}\text { Degree to which a person } \\
\text { has a favorable or } \\
\text { unfavorable evaluation of } \\
\text { the behavior in question } \\
\text { [20], in this case, online } \\
\text { purchasing. }\end{array}$} & \multirow{9}{*}{$\begin{array}{l}{[41],[75],} \\
{[83]}\end{array}$} \\
\hline & Using Internet to make my purchases is a good idea & & \\
\hline & My general opinion of e-commerce is positive & & \\
\hline & Using Internet to buy a product seems an intelligent idea to me & & \\
\hline & I take pleasure in buying online & & \\
\hline & I am inclined to buying online & & \\
\hline & I think that buying online is a good choice & & \\
\hline & I like buying online & & \\
\hline & I prefer buying online than going to a store & & \\
\hline \multirow{3}{*}{$\begin{array}{l}\text { Subjective } \\
\text { norm - SN }\end{array}$} & People who are important to me think that I should purchase online & \multirow{3}{*}{$\begin{array}{l}\text { Perceived social pressure } \\
\text { to perform or not to } \\
\text { perform the behavior [21], } \\
\text { in this case, online } \\
\text { purchasing }\end{array}$} & \multirow{3}{*}{$\begin{array}{l}{[27],[63]} \\
{[73],}\end{array}$} \\
\hline & People like me use to purchase online & & \\
\hline & $\begin{array}{l}\text { People who influence my behavior think that I should purchase } \\
\text { online }\end{array}$ & & \\
\hline \multirow{6}{*}{$\begin{array}{l}\text { Perceived } \\
\text { behavioral } \\
\text { control - } \\
\text { PBC }\end{array}$} & I have control over the whole Internet shopping process & \multirow{6}{*}{$\begin{array}{l}\text { Individuals' perception that } \\
\text { they have the knowledge, } \\
\text { resources, and } \\
\text { opportunities necessary } \\
\text { for Internet shopping [71] }\end{array}$} & \multirow{6}{*}{$\begin{array}{l}{[12],[32],} \\
{[37],[75],} \\
{[79]}\end{array}$} \\
\hline & I have the resources necessary to purchase online & & \\
\hline & I have the knowledge necessary to purchase on line & & \\
\hline & I can purchase online even if there were no one around to help me & & \\
\hline & I can purchase online reasonably well on my own & & \\
\hline & I can purchase online even if there were no support line & & \\
\hline \multirow{3}{*}{$\begin{array}{l}\text { Purchase } \\
\text { intention - } \\
\text { PI }\end{array}$} & If possible, I will try to purchase online & \multirow{3}{*}{$\begin{array}{l}\text { Predisposition of a person } \\
\text { to take any initiative to buy } \\
\text { before making the actual } \\
\text { decision [21], in this case, } \\
\text { the intention of online } \\
\text { purchasing }\end{array}$} & \multirow{3}{*}{$\begin{array}{l}\text { [31], [47], } \\
\text { [65], [75] }\end{array}$} \\
\hline & $\begin{array}{l}\text { It is likely that Internet will be the medium I use to make my } \\
\text { purchases in the near future }\end{array}$ & & \\
\hline & I intend to use Internet to buy a product in the near future & & \\
\hline
\end{tabular}




\subsection{Participants}

Our sample consists of 386 subjects, ranging from 18 to 58 years old ( $M=27.6$, SD $=7.3$ ), $46 \%$ women and $54 \%$ men, selected non-probabilistically. The questionnaire was sent by e-mail to undergraduate and graduate students of three universities of Bogota, Colombia, as well as to the alumni and employees database of one of those institutions. After completing the questionnaire, the participants could forward that information to other individuals. Originally, the questionnaire was sent to 9,883 persons, responses were received from 1,096. Only Colombian residents who had done Internet shopping during the last six months were selected. The invitation e-mail contained information about the study's main purpose, the voluntary nature of the participation, and the confidentiality of the information provided. Data was collected from October 2015 to February 2016.

\subsection{Measures}

The final questionnaire included 41 items adapted from TPB, TAR, TAM, and other e-commerce adoption models (table 1). All items use Likert-type six-point scales, in which 1 indicates completely disagree and 6 indicate completely agree. Item elaboration took place in five steps: (1) translation into Spanish; (2) validation by experts in technology management research and professors of marketing and consumer psychology; (3) wording proposal, followed by pilot face-to-face interviews with a random group of 30 students who completed the questionnaire and gave feedback on items, to ensure they were understandable and clear; (4) an online pilot test, sending the questionnaire revised version through Question Pro to a sample of 100 people to evaluate understanding, response time, and completion percentage, and making adjustments required for the final version; and (5) sending the questionnaire's final version to databases (table 1).

\subsection{Data Analysis}

Psychometric properties of scales were examined using Cronbach's Alpha coefficient and exploratory factor analysis (SPSS 19.0). The next step taken was to analyze the relationships postulated in the hypothesis model using the Bayesian estimation approach. In this section we provide the model details used in our analysis. The Bayesian estimation approach for this problem encompasses the following elements:

1. A variable-specific parameter set, $\mathrm{d}=\left\{\mathrm{a}_{j}\right\}$, represents the average level of the variable across the population. An average of zero indicates Likert-scales built around population central values.

2. A model misspecification noise term, $E_{1}$, with precision parameter $\mathbf{T}$, which accounts for potential variables and/or relationships not included in our model. This is assumed to be Gaussian, and represented as $\mathrm{N}\left(\mathrm{E}_{\mathrm{j}}[0, \mathrm{~T})\right.$. Any systematic bias will be captured by the a parameters.

- In this latent space, $U_{i, j}$ are assumed to be linearly related to each other through linear parameters $\beta=\left\{\beta_{j, k}\right]$. This assumption can be easily relaxed without additional model complexity. Other variables or interactions (and relationships) can also be easily integrated in this model.

- The Bayesian model specification is completed with hyper priors for the remaining parameters $\theta=\left\{\alpha_{n}, \beta_{x}\right\}_{\text {. }}$. Details are provided in Appendix 1. Information available from prior studies can easily be incorporated through these hyper priors.

The joint distribution can be expressed in compact statistical form as follows:

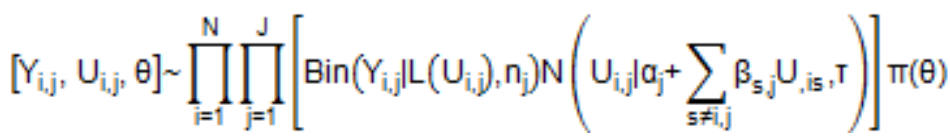

Note that the graphical model specification will drive some of those $\beta_{5, j}$ in the above latent space to be set to zero. The hypothesized model is assumed to function under the error-free latent variables $U$ rather than under the observed-with-error data $Y$. 


\section{Results}

Descriptive analysis, reliability and validation of each variable were conducted to evaluate the properties of the scales. Subsequently we evaluated the hypothesized model using Bayesian approach.

\subsection{Properties of the Scales}

The analysis of item-total correlations showed positive and significant relationships between all the items of each scale and the total scale, which suggests that all items measure the same construct. In fact, Cronbach's alpha coefficients were at least 0.722 and, in each case, removing any item reduces the value of alpha coefficients, which demonstrates an excellent internal consistency (Table 2). Regarding construct validity of instruments, the correlation matrices values were greater than 0.32 and the anti-image correlation matrices values were close to zero.

Table 2: Properties if the scales

\begin{tabular}{|l|c|c|c|c|c|c|c|c|c|c|c|c|c|}
\hline & $\mathrm{N}$ & $\mathrm{M}$ & $\mathrm{SD}$ & $\mathrm{\alpha}$ & 1 & 2 & 3 & 4 & 5 & 6 & 7 & 8 & 9 \\
\hline 1.Purchase intention - PI & 372 & 4.9 & 1.1 & .84 & 1 & & & & & & & \\
\hline $\begin{array}{l}\text { 2.Attitude to e-commerce } \\
\text { - ATT }\end{array}$ & 380 & 4.5 & 1.1 & .94 & $.73^{*}$ & 1 & & & & & & \\
\hline $\begin{array}{l}\text { 3.Perceived behavioral } \\
\text { control -PBC }\end{array}$ & 381 & 4.9 & .90 & .85 & $.59^{*}$ & $.58^{*}$ & 1 & & & & & & \\
\hline 4.Subjective norm - SN & 386 & 4.1 & 1.2 & .87 & $.66^{*}$ & $.62^{*}$ & $.47^{*}$ & 1 & & & & & \\
\hline $\begin{array}{l}\text { 5.Perceived ease of use } \\
\text { - PE }\end{array}$ & 383 & 4.9 & .92 & .84 & $.54^{*}$ & $.65^{*}$ & $.64^{*}$ & $.46^{*}$ & 1 & & & & \\
\hline $\begin{array}{l}\text { 6.Perceived usefulness } \\
\text { - PU }\end{array}$ & 382 & 4.5 & 1.0 & .89 & $.61^{*}$ & $.77^{*}$ & $.52^{*}$ & $.52^{*}$ & $.66^{*}$ & 1 & & & \\
\hline $\begin{array}{l}\text { 7.Perceived self-efficacy } \\
\text { - PSE }\end{array}$ & 382 & 5.2 & .90 & .81 & $.75^{*}$ & $.65^{*}$ & $.64^{*}$ & $.58^{*}$ & $.58^{*}$ & $.51^{*}$ & 1 & & \\
\hline $\begin{array}{l}\text { 8.Acceptance of Internet } \\
\text { - AOI }\end{array}$ & 386 & 5.5 & .64 & .87 & $.43^{*}$ & $.39^{*}$ & $.41^{*}$ & $.23^{*}$ & $.55^{*}$ & $.33^{*}$ & $.54^{*}$ & 1 & \\
\hline $\begin{array}{l}\text { 9.Internet use frequency } \\
\text {-IUF }\end{array}$ & 386 & 5.3 & .82 & .72 & $.32^{*}$ & $.37^{*}$ & $.47^{*}$ & $.21^{*}$ & $.57^{*}$ & $.34^{*}$ & $.45^{*}$ & $.64^{*}$ & 1 \\
\hline
\end{tabular}

$\mathrm{M}=$ mean, $\mathrm{SD}=$ standard deviation, $\alpha=$ Cronbach's alpha

Table 3. Descriptive statistics of the posterior distribution of Bayesian model parameters

\begin{tabular}{|l|l|l|l|l|l|l|l|}
\hline & Mean & SD & $\begin{array}{l}\text { Percentile } \\
2.5\end{array}$ & $\begin{array}{l}\text { Percentil } \\
\text { e 5.0 }\end{array}$ & $\begin{array}{l}\text { Percentile } \\
95.0\end{array}$ & $\begin{array}{l}\text { Percentile } \\
97.5\end{array}$ & $\begin{array}{l}\text { Result of } \\
\text { hypothesis }\end{array}$ \\
\hline alpha [1] - PI & -1.52 & 0.274 & -2.079 & -1.987 & 1.085 & -0.9997 & \\
\hline alpha [2] - ATT & -0.29 & 0.104 & -0.4978 & -0.4657 & -0.1226 & -0.09156 & \\
\hline alpha [3] - PBC & 0.515 & 0.093 & 0.3322 & 0.3607 & 0.6705 & 0.7004 & \\
\hline alpha [4] - SN & 0.969 & 0.047 & 0.8766 & 0.8909 & 1.049 & 1.065 & \\
\hline alpha [5] - PEOU & 0.507 & 0.095 & 0.3249 & 0.3546 & 0.663 & 0.6949 & \\
\hline alpha [6] - PU & -.069 & 0.096 & -0.2569 & 0.2248 & 0.09107 & 0.1245 & \\
\hline alpha [7] - PSE & -0.30 & 0.86 & -4.425 & -4.316 & -1.489 & -1.31 & \\
\hline alpha [8] - AOI & 2.937 & 0.067 & 2.812 & 2.829 & 3.049 & 3.07 & \\
\hline alpha [9] - IUF & -0.50 & 0.922 & -1.743 & -1.695 & 1.187 & 1.221 & \\
\hline beta21-H1:ATT $\rightarrow$ PI & 0.731 & 0.238 & 0.2744 & 0.3478 & 1.133 & 1.212 & Confirmed \\
\hline beta42 - H2: SN $\rightarrow$ ATT & 0.376 & 0.080 & 0.2208 & 0.2447 & 0.5088 & 0.5339 & Confirmed \\
\hline beta31- H3 PBC $\rightarrow$ PI & 0.1094 & 0.1544 & 0.00209 & -0.1983 & 0.1105 & 0.413 & Not Confirmed \\
\hline beta52 - H4:PEOU $\rightarrow$ ATT & 0.262 & 0.079 & 0.1069 & 0.134 & 0.3925 & 0.4143 & Confirmed \\
\hline beta56 - H7:PEOU $\rightarrow$ PU & 0.702 & 0.096 & 0.5194 & 0.5437 & 0.8658 & 0.8937 & Confirmed \\
\hline beta61 - H6:PU $\rightarrow$ PI & 0.135 & 0.265 & -0.3899 & -0.3032 & 0.5676 & 0.6513 & Not confirmed \\
\hline beta62 - H5:PU $\rightarrow$ ATT & 0.664 & 0.089 & 0.493 & 0.5182 & 0.8116 & 0.8403 & Confirmed \\
\hline beta73 - H10:PSE $\rightarrow$ PBC & 0.575 & 0.041 & 0.4955 & 0.5083 & 0.6457 & 0.6587 & Confirmed \\
\hline beta75 - H9:PSE $\rightarrow$ PEOU & 0.604 & 0.042 & 0.5213 & 0.5344 & 0.674 & 0.6896 & Confirmed \\
\hline beta76 - H8:PSE $\rightarrow$ PU & 0.072 & 0.069 & -0.0646 & -0.04356 & 0.1832 & 0.203 & Not confirmed \\
\hline beta87 - H12:AOI $\rightarrow$ PSE & 1.056 & 0.465 & 0.1549 & 0.2029 & 1.746 & 1.932 & Confirmed \\
\hline beta89 - H13:AOI $\rightarrow$ IUF & -0.39 & 0.323 & -1.033 & -1.021 & 0.01373 & 0.02754 & Not confirmed \\
\hline beta97 - H11:IUF $\rightarrow$ PSE & -1.48 & 0.372 & -2.161 & -2.098 & -0.8588 & -0.742 & Not confirmed \\
\hline Tau $-\tau$ & 1.81 & 0.133 & 1.59 & 1.619 & 2.061 & 2.118 & \\
\hline
\end{tabular}

\subsection{Bayesian Estimation}

The proposed model hypothesized 13 relations between variables. Results showed positive and significant relations between eight pairs of variables (measured as those linear relationship variables $\beta$ with the central $95 \%$ high 
probability density interval -HPD to the right of zero): acceptance of Internet as predictor of perceived self-efficacy; perceived self-efficacy as predictor of perceived ease of use of e-commerce and perceived behavioral control; perceived ease of use of e-commerce, perceived usefulness of e-commerce, and subjective norm as predictors of attitude toward e- commerce; and attitude toward e-commerce as predictor of purchase intention, and perceived ease of use as a predictor of perceived usefulness. Three relations were found marginally positive and nonsignificant (perceived self-efficacy as predictor of perceived usefulness of e-commerce; perceived usefulness of ecommerce and perceived behavioral control as predictors of purchase intention) and two relationships were found negative (acceptance of Internet as predictor of Internet frequency of use, and Internet frequency of use as predictor of perceived self-efficacy). Some of the Markov Chain Monte Carlo (MCMC) output is provided in Table 3 . The interpretation of the different variables is straightforward on the basis of the SEM structure in (4) and the model specification in the Appendix A and B:

1) Ui,j represents the unknown latent variable j for individual $i$, which we only observed with error as $Y i, j$

2) aj represents the average Likert value for latent variable j

3) $\beta \mathrm{j}, \mathrm{k}$ represents the linear influence of latent variable $\mathrm{j}$ on latent variable $\mathrm{k}$. Nonzero values are indicative of linear relationships being validated.

4) $\pi$ represents the common misspecification precision parameter

\section{Discussion}

Our results demonstrate the relevance of the extended model tested to explain online shopping intention among Colombian residents, by integrating TRA and TAM, and including perceived self-efficacy in using Internet, as well as a factor related to previous experience with the Internet. Specifically, regarding TRA and TPB variables, as expected from such theoretical models and findings from different studies, for instance [11], [33], [35], [38], [45], [58], [59], [60], [61], [66], [71], [73] results demonstrate that attitude to e-commerce directly predicts the online purchase intention. In addition, as hypothesized, the subjective norm directly predicts attitude to e-commerce. This is consistent with findings reported by [38], in their study on e-shopping acceptance.

According to TRA and TPB, as well as such models as Unified Technology of Acceptance and Use Technology (UTAUT) [79], subjective norm should be directly related to behavioral intention, which has been confirmed by different researchers, such as [33], [38], [71], [60]. However, by following TAM [32], in the present study, such a direct relationship was not expected. Instead, and as confirmed by this study results, subjective norm indirectly influences the intention, through its direct relation from attitude to e-commerce. In this sense, it is expected to be a relationship between subjective norm and attitude [3]; and the effect of subjective norm on behavioral intention is mediated by attitude [5].

Contradicting theoretical expectations and findings reported by such authors the TPB variable perceived behavioral control was found marginally and non-significantly related to online purchase intention [24] , [38], [60], [72]. This result is consistent with [33], who found that behavioral control did not significantly predict the intention of adopting ecommerce among Chilean small business leaders. Our findings suggest that in the context of e-shopping, a better alternative would be to apply a more parsimonious model such as TRA. However, this does not invalidate TPB since, as indicated by the authors, the relative importance and weight of the model's different variables in predicting behavioral intention is expected to vary according to the behavior under study, the culture, and specific characteristics of the studied population [4].

Regarding TAM key variables, as expected from the theoretical model and the findings reported by different authors, PU directly predicted the attitude to e-commerce [25], [34], [38], [45], [61], [72], [74], [78]. However, against what was hypothesized by TAM and other authors, PU did not directly and significantly predict the intention of buying online [11], [24], [25], [31], [38], [45], [61], [66], [74], [79]. The impact of PU over BI was indirect through its effect on attitude toward e-commerce, which is consistent with findings reported in Spain [34] and Colombia [73].

The perceived ease of use of e-commerce directly predicted the attitude toward to e-commerce, as hypothesized following TAM and as found by [11], [25], [38], [45], [66]. As expected according to TAM and findings reported PEOU directly predicted PU [46], [61], [65], [73]. According to the findings reported by [35], studying the intention of online purchasing among frequent Internet users, the present study found a strong, direct and significant relation between perceived self-efficacy and perceived ease of use of e-commerce. However, contrary to expectations and these authors' findings, PSE did not significantly predict PU. In turn, consistent with findings by [34], perceived self-efficacy was predicted by acceptance of the Internet, but not by frequency of use of Internet (which differs from these authors' findings). A plausible explanation could be that the sample was limited to experienced online customers, which restricted the variability of information for inference, since all of them were frequent users of the Internet. Finally, the frequency of use of Internet was not predicted by acceptance of the Internet, which is not consistent with these author's findings among experienced e-customers. 


\section{Conclusions}

The main objective of this research was to explain intentions to shop online in Colombia, by means of a theoretical integration of TRA, TPB y TAM. Although these models, whether integrated or independently, constitute the most important theoretical references in studying behavioral intention, their authors suggest possible variations in the explanatory contribution of each variable, according to the specific context of study. The present study provides evidence to understand, in the context of a Latin American emerging market such as Colombia, which variables contribute to the explanation of the adoption of e-commerce as a retail channel.

Individuals showing more acceptance of the Internet perceive themselves as having more abilities and resources for successfully performing those tasks related to online purchasing (self-efficacy). These individuals, in turn, perceive online purchasing as requiring a minimum effort, finding the Internet as an easy way of buying (ease of use), and also perceive that they have the knowledge and resources needed to autonomously perform the behavior of online purchasing (behavioral control).

Consumers who perceive that e-commerce is easy also perceive that using the Internet to shop is beneficial, improving the outcome of the buying task by making it more efficient and quick (perceived usefulness). Both aspects contribute to increase the probability of a positive evaluation of Internet shopping (attitude), which in turn increases the probability of online purchasing in the near future (intention). Likewise, individuals who consider that people relevant to them think that they should buy online are more likely to show a positive attitude to e-commerce, and consequently, are more likely to perform the behavior of online purchasing.

Another important contribution of this study is that it is the first research, to our knowledge, applying a Bayesian approach to test an integrative research hypothesis, based upon the three theories for studying the behavioral intention of online purchasing. This approach allows us to overcome the limitations of traditional multivariate methods in this field [1], and produces results more consistent with the theoretical formulation of the main antecedent of the proposed models, TRA and TRP [19], which emphasize predicting probability instead of causality.

The results of the present study, according to its theoretical foundations, show that attitude remains the main variable in predicting the occurrence of the online purchasing behavior. Certainly, other variables could have direct effects on the intention of online purchasing, but their contribution is significant only through the attitude to ecommerce. Thus, understanding the determinants of the individual's attitude remains the key to developing persuasion strategies to increase a favorable attitude towards shopping and, consequently, increasing the probability of occurrence (intention) of the behavior of online purchasing. [6] stated that attitudes depended on the strength of the beliefs referred to the attitudinal object, understood as the subjective probability of the association between the object and an attribute. In this study, the relevant beliefs are represented in the evaluated model by the perceived usefulness, the perceived ease of use, and the subjective norm referred to a particular behavior. These beliefs refer to the attributes of online purchasing, their favorable outcomes, easiness, usefulness, and its evaluation by other persons relevant to the subject. This suggests that communicating the advantages of online shopping over traditional channels might contribute to creating associations between e-commerce and positive attributes and, thus, promoting favorable attitudes toward performing the behavior of online purchasing.

Among the limitations of this study it should be noted that due to the lack of research focused on determining the factors that influence the acceptance of e-commerce in Latin America, and the little development of electronic commerce in the context in which this research was carried, this paper simply provides an approach to the understanding of the determinants of intention toward online purchases. Hence our results provide a starting point for further specific research that assesses how the impact of specific determinants changes depending on aspects such as the type of product or service.

Although the proposed model worked satisfactorily for understanding the factors explaining the intention of online purchasing, it is necessary to continue including and controlling for other variables that could increase the predictive power. For example, the increased use of different devices for accessing the Internet -PC, Laptop, Tablet, Cellphone or Digital TV- could have a differential effect on buying disposition. This is of crucial importance for companies willing to compete in the e-market, which requires more specific information for managing their digital channels. Likewise, such variables inherent to e-commerce (type of product, utilitarian vs hedonic products/services, quality, site, previous online shopping experiences, risk, privacy, security, navigation) and consumers (motivation, disposition to innovate, experience, and satisfaction with e-commerce) could be differential determinants or moderators of the theoretically proposed relationship, hence the need for future research to include these variables in order to predict customer behaviors more precisely.

Also, it seems advisable to include other external variables studied in this context [82] such as trust and perceived safety, which could affect the discourse on the perceived benefits (ease of use and usefulness) provided by the retail channel for developing more persuasive arguments about the strengths of these alternatives for customers [11], [45], [73], [74]. 
On the other hand, according to theoretical expectations, PSE influenced PU and PEOU, but its effect was greater on the latter one. This calls for the need to measure other variables that could affect this factor of intrinsic motivation since, as defined and measured in this and other studies [35], [83] perceived self-efficacy only refers to the use of the Internet, and not to other aspects of e-commerce that could affect the perception of effort in transactions (payment, for instance).

Finally, the relationship PSE $\rightarrow \mathrm{PU}(\mathrm{H} 8)$ and $\mathrm{AOI} \rightarrow \mathrm{IUF}(\mathrm{H} 13)$ were not supported. Although these relationships have been established theoretically, they have been little investigated. This will require the development of additional studies to understand more thoroughly the relationship between these variables.

\section{Acknowledgments}

We would like to gratefully acknowledge the support of the Research Group of Colegio de Estudios Superiores de Administración - CESA. In particular our thanks to Prof. David van der Woude for his support in the review and comments. We would also like to thank Professor Laura Gunn for her comments and suggestions.

\section{References}

[1] M. A. Aggorowati, N. Iriawan, Suhatorno and H. Gautama, Restructuring and expanding technology acceptance model: Structural equation model and Bayesian approach, American Journal of Applied Sciences, vol. 9, no. 4, pp. 496-504, 2012.

[2] R. Agrawal and J. Prasad, Are individual differences germane to the acceptance of new information technologies? Decision Sciences, vol. 30, no. 2, pp. 361-391, 1999.

[3] I. Ajzen. (2006, April) TPB diagram. People Umass. [Online]. Available: http://people.umass.edu/aizen/tpb. diag.html

[4] I. Ajzen and M. Fishbein, Questions raised by a reasoned action approach: Comment on Ogden, Health Psychology, vol. 23, no. 4, pp. 431-434, 2004.

[5] I. Ajzen, The theory of planned behavior, Organizational Behavior and Human Decisions Processes, vol. 50, no. 2, pp. 179-211, 1991.

[6] I. Ajzen and M. Fishbein, Understanding Attitudes and Predicting Social Behavior. New Jersey: Prentice Hall, 1980.

[7] J. Allik, A mixed-binomial model for likert-type personality measures, Frontiers in Psychology, vol. 5, no. 371, 2014.

[8] A. Arbelaez. (2014, May) 19 datos que usted no sabía sobre internet en Colombia. Enter.co. [Online]. Available: http://www.enter.co/cultura-digital/colombia-digital/19-datos-que-usted-no-sabia-sobre-internet-encolombia/

[9] R. Bagozzi and P. Warshaw, Trying to consume, Journal of Consumer Research, vol. 17, no. 2, pp. 127-140, 1990.

[10] A. Bandura, Self-efficacy: The Exercise of Control. New York: W.H. Freeman, 1997.

[11] G. Baptista and T. Oliveira, A weight and a meta-analysis on mobile banking acceptance research, Computers in Human Behavior, vol. 63, pp. 480-489, 2016.

[12] A. Bhattacherjee, Understanding information systems continuance: An expectation-confirmation model, MIS Quarterly, vol. 25, no. 3, pp. 351-370, 2001.

[13] I. Benbasat and A. Dexter, An investigation of the effectiveness of color and graphical information presentation under varying time constraints, MIS Quarterly, vol. 10, no. 1, pp. 59-83, 1986.

[14] I. Benbasat, A. Dexter and P. Todd, An experimental program investigating color-enhanced and graphical information presentation: An integration of the findings, Communications of the ACM, vol. 29, no. 11, pp. 10941105,1986

[15] H. Ben-Shabat, P. Nildoroushan, C. Yuen, and M. Moriarty. (2015) Global retail e-commerce keeps on clicking. Atkearney. [Online]. Available: https://www.atkearney.com/documents/10192/5691153/Global+Retail+E-Comm erce+Keeps+On+Clicking.pdf/abe38776-2669-47ba-9387-5d1653e40409

[16] H. O. B. D. Bodur and E. Coupey, Belief, affect and attitude: Alternative models of the determinants of attitude, Journal of Consumer Psychology, vol. 9, no. 1, pp. 17-28, 2000.

[17] G. Bruner and A. Kumar, Explaining consumer acceptance of handheld Internet devices, Journal of Business Research, vol. 58, no. 5, pp. 553-558, 2005.

[18] Cámara de Comercio Electrónico de Colombia. (2015, January) El 2,19\% del PIB de Colombia de 2013 corresponde a transacciones no presenciales/ecommerce. Cámara Colombiana de Comercio Electrónico. [Online]. Available: http://ccce.org.co/noticias/el-219-del-pib-de-colombia-de-2013-corresponde-comercio-electronico

[19] A. K. Chandra and D. K. Sinha, Factors affecting the online shopping behavior: A study with reference to Bihlai Durg, International Journal of Advanced Research in Management and Social Sciences, vol. 2, no. 5, pp. 160177, 2013.

[20] L.D. Chen, M. Gillenson and D. Sherrell, Enticing online consumers: An extended technology acceptance perspective, Information Management, vol. 8, no. 709-719, p. 39, 2002. 
[21] M. D. Clemes, C. Gan and J. Zhang, An empirical analysis of online shopping adoption in Beijing, China, Journal of Retailing and Consumer Services, vol. 21, no. 3, pp. 364-37, 2014.

[22] D. Compeau and C. Higgins, Application of social cognitive theory to training for computer skills, Information System Research, vol. 6, no. 2, pp. 118-143, 1995.

[23] F. D. Davis, User acceptance of information technology: System characteristics, user perceptions and behavioral impacts, International Journal of Man-Machine Studies, vol. 38, no. 3, pp. 475-487, 1993.

[24] F. D. Davis, Perceived usefulness, perceived ease of use, and user acceptance of information technology, MIS Quarterly, vol. 13, no. 3, pp. 319-340, 1989.

[25] F. D. B. R. Davis and P. Warshaw, User acceptance of computer technology: A comparison of two theoretical models, Management Science, vol. 8, no. 35, pp. 982-1003, 1989.

[26] P. Dickson and P. Miniard, A further examination of two laboratory test of the extended Fishbein attitude model, Journal of Consumer Research, vol. 4, no. 4, pp. 261-266, 1978.

[27] Fishbein and I. Ajzen, Belief, Attitude, Intention, and Behavior: An Introduction to Theory and Research. MA: Addison-Wesley, 1975.

[28] W. Doll, J, A. Hendrickson and X. Deng, Using Davis's perceived usefulness and ease-of-use instruments for decision making: A confirmatory and multigroup invariance analysis, Decision Sciences, vol. 29, no. 4, pp. 839869, 1998.

[29] A. Fosk. (2013, August) 2013 Colombia digital future in focus. ComScore. [Online]. Available: http://www.comscore.com/Insights/Presentations-and-Whitepapers/2013/2013-Colombia-Digital-Future-in-Focus?cs edgescape cc=US

[30] Fnbox. (2015) Presentations. Fnbox. [Online]. Available: http://www.fnbox.com/presentations.html

[31] D. Gefen, E. Karahanna and D. W. Straub, Trust and TAM in online shopping: An integrated model, MIS Quarterly, vol. 27, no. 1, pp. 51-90, 2003.

[32] J. F. George, The theory of planned behavior and Internet purchasing, Internet Research, vol. 14, no. 3, pp. 198-212, 2004

[33] E. Grandón, S. Nasco and P. Mykytyn, Comparing theories to explain e-commerce adoption, Journal of Business Research, vol. 64, no. 3, pp. 292-298, 2011.

[34] B. Hernández, J. Jiménez and M. J. Martín, Age, gender and income: Do they really moderate online shopping behavior? Online Information Review, vol. 35, no. 1, pp. 113-133, 2011.

[35] B. Hernández, J. Jiménez y M. J. Martin, Customer behavior in electronic commerce: The moderating effect of e-purchasing experience, Journal of Business Research, vol. 63, no. 9, pp. 964-971, 2010.

[36] A. Herrero, I. Rodríguez del Bosque and M. D. M. García de los Salmones, La compatibilidad percibida en la adopción del comercio electrónico B2C: Un análisis sobre la base del modelo de aceptación de tecnología, in Proceedings XIV Congreso Nacional de ACEDE, Murcia, 2004, pp. 1-30.

[37] H. J. Huh, T. T. Kim and R. Law, A comparison of competing theoretical models for understanding acceptance behavior of information systems in upscale hotels, International Journal of Hospitality Management, vol. 28, no. 1 , pp. 121-134, 2009.

[38] J. Ingham, J. Cadieux and A. Berrada, E-shopping acceptance: A qualitative and meta-analityc review, Information \& Management, vol. 52, no. 1, pp. 44-60, 2015.

[39] Internet World Stat. (2016, December) Internet world stats. Internet World Stats, Usage and Population Statistics. [Online]. Available: http://www.internetworldstats.com/

[40] C. Jimenez. (2015, February) 7 tendencias digitales para el 2015. Tendencias Digitales. [Online]. Available: http://tendenciasdigitales.com/7-tendencias-digitales-para-el-2015/

[41] E. Karahanna, D. W. Straub and N. L. Chervany, Information technology Adoption across time: A crosssectional comparison of pre-adoption and post-adoption beliefs, MIS Quarterly, vol. 23, no. 2, pp. 183-213, 1999.

[42] H. Kelman, Compliance, identification, and internalization: Three processes of attitude change, Journal of Conflict Resolution, vol. 2, no. 1, pp. 51-60, 1958.

[43] W. King and J. He, A meta-analysis of the technology acceptance model, Information and Management, vol. 43, pp. 740-755, 2006.

[44] J. Kruschke, H. Aguinis and H. Joo, The time has come: Bayesian methods for data analysis in the organizational sciences, Organizational Research Methods, vol. 15, no. 4, pp. 722-752, 2012.

[45] A. Kumar, P. Sikdar and M. and Alam, KE-Retail adoption in emerging markets: Applicability of an integrated trust and technology acceptance model, International journal of business Research, vol. 12, no. 3, pp. 44-67, 2016.

[46] Y. K. K. Lee, K. Kosar and K. Larsen, The technology acceptance model: Past, present, and future, Communications of the Association for Information Systems, vol. 12, no. 1, pp. 752-780, 2003.

[47] M. Limayem, M. Khalifa and A. Frini, What makes consumers buy from Internet? A longitudinal study of online shopping, IEEE Transactions on Systems, Man and Cybernetics, Part A: Systems and Humans, vol. 30, no. 4, pp. 421-432, 2000.

[48] B. L. López and B. J. López, Estudio comparado de las estimaciones de dos versiones del modelo de aceptación de la tecnología (TAM) mediando los programas AMOS y PLS., Investigaciones Europeas de Dirección y Economía de la Empresa (IEDEE), vol. 12, no. 3, pp. 95-110, 2006.

[49] R. Lutz, An experimental investigation of causal relations among cognitions, affect, and behavioral intention, Journal of Consumer Research, vol. 3, no. 4, pp. 197-208, 1977. 
[50] Y. Malhotra and D. Galletta, Extending the technology acceptance model to account for social influence: Theoretical bases and empirical validation, in Proceedings of the 32nd International Conference on System Sciences, Hawaii, 1999.

[51] G. Maruyama, Basics of Structural Equation Modeling. Thousands Oaks CA: Sage, 1997.

[52] K. Mathieson, Predicting user intentions: Comparing the technology acceptance model with the theory of planned behavior, Information Systems Research, vol. 2, no. 3, pp. 173-191, 1991.

[53] P. McCole, E. Ramsey and J. Williams, Trust considerations on attitudes towards online purchasing: The moderating effect of privacy and security concerns, Journal of Business Research, vol. 63, no. 9, pp. 10181024, 2010.

[54] P. Miniard and J. Cohen, Isolating attitudinal and normative influences in behavioral intentions models, Journal of Marketing Research, vol. 16, no. 1, pp. 102-110, 1979.

[55] Miniwatts Marketing Group. (2015, November) Host free webinars today. Internet World Stats. [Online]. Available: http://www.internetworldstats.com/

[56] G. Molina, M. Bayarri and J. Berger,Statistical inverse analysis of a network microsimulator, Technometrics 47, vol. 47, p. 388-398, 2005.

[57] G. Moore and I. Benbasat, Development of an instrument to measure the perception of adopting an information technology innovation, Information System Research, vol. 2, no. 3, pp. 199-222, 1991.

[58] S. Musleh, G. Marthandan y N. Aziz, An extension of UTAUT model for Palestine e-commerce, International Journal of Electronic Business, vol. 12, no. 1, pp. 95-115, 2015.

[59] S. Nasco, E. Grandón-Toledo and P. Mykytyn, Predicting electronic commerce adoption in Chilean SMEs, Journal of Business Research, vol. 61, no. 6, pp. 697-705, 2008.

[60] Nasir, B. Ranjbarian and A. Ansari, Analysis of the effective factors on online purchase intention through theory of planned behavior, International Journal of Academic Research in Business and Social Sciences, vol. 4, no. 4, pp. 374-382, 2014.

[61] A. A. Nathier, An empirical investigation to validate the technology acceptance model (TAM) in explaining intentions to shop online in Saudi Arabia using SEM, Jordan Journal of Business Administration, vol. 10, no. 2, pp. 317-332, 2014.

[62] T. Novak and D. Hoffman, New metrics for new media: Toward the development of Web measurement standards, World Wide Web Journal, vol. 2, no. 1, pp. 213-246, 1997

[63] H. Nysveen, P. E. Pedersen and H. Thorbjørnsen, Explaining intention to use mobile chat services: Moderating effects of gender, Journal of Consumer Marketing, vol. 22, no. 5, pp. 247-256, 2005

[64] F. J. Pascual-Miguel, Á. F. Agudo-Peregrina and J. Chaparro-Peláez, Influences of gender and product type on online purchasing, Journal of Business Research, vol. 68, no. 7, pp. 1550-1556, 2015.

[65] P. A. Pavlou, Consumer acceptance of electronic commerce: Integrating trust and risk with the technology acceptance model, International Journal of Electronic Commerce, vol. 7, no. 3, pp. 101-134, 2003.

[66] T. Perea y Monsuwé, B. G. C. Dellaert and K. R. de Ruyter, What drives consumers to shop online? A literature review, International Journal of Service Industry Management, vol. 15, no. 1, pp. 102-121, 2004

[67] G. Rigopoulos, J. Psarras and D. Askounis, A TAM model to evaluate user's attitude towards adoption of decision support systems, Journal of Applied Sciences, vol. 8, no. 5, pp. 899-902, 2008.

[68] B. Roos, Binomial approximation to the Poisson binomial distribution: The krawtchouk expansion, Theory of Probability \& Its Applications, vol. 45, no. 2, pp. 258-272, 2001.

[69] J. Rost, Rating scale analysis with latent class models, Psychometrika, vol. 53, no. 3, pp. 327-348, 1988.

[70] M. Ryan, Behavioral intention formation: The interdependency of attitudinal and social influence variables, Journal of Consumer Research, vol. 9, no. 3, pp. 263-278, 1982

[71] B. Sheppard, J. Hartwick and P. Warshaw, The theory of reasoned action: A meta-analysis of past research with recommendations for modifications and future research, Journal of Consumer Research, vol. 15, no. 3, pp. 325-342, 1988.

[72] H. Sun and P. Zhang, The role of moderating factors in user technology acceptance, International Journal of Human-Computer Studies, vol. 64, no. 2, pp. 53-78, 2006.

[73] J. Tavera and B. Londoño, Factores determinantes de la aceptación tecnológica del e-commerce en países emergentes, Revista de Ciencias Estratégicas, vol. 22, no. 3, pp. 101-119, 2014

[74] J. Tavera-Mesías, J. Sánchez-Giraldo and B. Ballesteros-Díaz, Aceptación del e-commerce en Colombia: Un estudio para la ciudad de Medellín, Revista Facultad de Ciencias Económicas: Investigación y Reflexión, vol. 19, no. 2, pp. 9-23, 2011.

[75] S. Taylor and P. Todd, Understanding information technology usage: A test of competing models, Information Systems Research, vol. 6, no. 2, pp. 144-176, 1995.

[76] K. Teerapabolarn, An improvement of Poisson approximation for sums of dependent Bernoulli random variables, Communications in Statistics-Theory and Methods, vol. 43, no. 8, pp. 1758-1777, 2014

[77] T. Teo, V. Lim and R. Lai, Intrinsic and extrinsic motivation in Internet usage, Omega The International Journal of Management Science, vol. 27, no. 1, pp. 25-37, 1999.

[78] P. y M. Toñita, B. Dellaert and K. de Ruyter, What drives consumers to shop online? A literature review, International Journal of Service Industry Management, vol. 15, no. 1, pp. 102-121, 2004.

[79] V. Venkatesh, Morris, D. G. M.G. and F. Davis, User acceptance of information technology: toward a unified view, MIS Quarterly, vol. 27, no. 3, pp. 425-478, 2003.

[80] V. Venkatesh and M. Morris, Why don't men ever stop to ask for directions? Gender, social influence, and their role in technology acceptance and usage behavior, MIS Quarterly, vol. 24, no. 1, pp. 115-139, 2000. 
[81] C.-H. Wu, An empirical study on the transformation of likert-scale data to numerical scores, Applied Mathematical Sciences, vol. 1, no. 58, p. 2851-2862, 2007.

[82] Q. Yang, C. L. L. Pang, D. Yen and M. Tarn, Exploring consumer perceived risk and trust for online payments: An empirical study in China's younger generation, Computers in Human Behavior, vol. 50, pp. 9-24, 2015.

[83] J. Yu, I. Ha, M. Choi and J. Rho, Extending the TAM for a t-commerce, Information \& Management, vol. 42, no. 7, pp. 965-976, 2005. 


\section{Appendix A: Model Specification}

In this section we provide the model details used in our analysis. We propose a Bayesian estimation approach for this problem, which encompasses the following elements built on a hierarchical approach:

- Let $Y_{i, j}$ be the aggregate response value from individual $\mathrm{i}=1_{n} \ldots \ldots N$ of variable $\mathbf{j}=1_{n} \ldots \ldots$ J. Each individual is assumed to have conditionally independent probabilities $P_{i j}$ driving their responses within each variable. Following to [81], we assume a binomial parsimonious likelihood for the observed responses $Y_{i, j} \sim \operatorname{Bin}\left(Y_{i, j} \mid n_{j p} P_{i, j}\right)$.

- We map one-to-one those probabilities from a set of unknown latent drivers $U_{i, j} \in R$, also individual- and variable-specific, using a logistic link function $L(x)=\exp (x) /(1+\exp (x))$.

- These latent drivers are assumed to relate to each other following the graphical model specification hypothesized in this paper, with the addition of two elements:

- (1) A variable-specific parameter set $\alpha=\left\{\alpha_{j}\right\}$, representing the average levels of the variables across the population. $\mathrm{a}_{\mathrm{j}}=0$ indicates Likert-scales for variable $\mathrm{j}$ built around population central values.

- (2) A model misspecification noise term, $E_{\mathrm{j}}$, with precision parameter $\mathrm{T}$, which accounts for potential variables and/or relationships not included in this proposed model. This is assumed to be Gaussian, and represented as $\mathrm{N}\left(\mathrm{E}_{\mathrm{j}}[0, \mathrm{~T})\right.$.

- In this latent space, $\mathrm{U}_{\mathrm{i} j \mathrm{j}}$ are assumed linearly related to each other through linear parameters $\beta=\left\{\beta_{\mathrm{j} k}\right\}$. This assumption can be easily relaxed without computational burden. Other variables or interactions (and relationships) can also be easily integrated in this model.

- $\quad$ The Bayesian model specification is completed with hyper priors for the remaining parameters $\theta=\left\{\alpha_{s} \beta_{s} \tau\right\}$. These hyperpriors are assumed non-informative, but prior information can be easily incorporated, which is more meaningful in small sample studies or studies where previous information/pilot studies have been informed.

The joint distribution can be expressed in compact statistical form as follows:

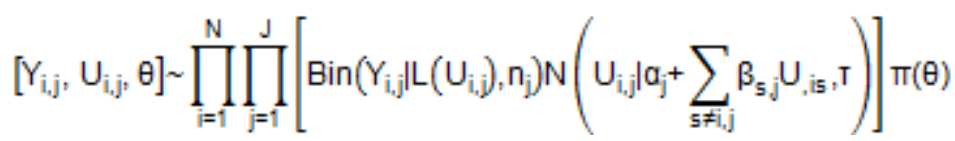

Note that the graphical model specification will drive that some of those $\beta_{s_{0}, j}$ in the above latent space to be set to zero. 


\section{Appendix B: Model Approach and Design}

Let $Q_{i, k \mathbb{~}}$ be the Likert-scale response (with up to $n_{j, k \notin}=6$ numerical categories in our particular application) of individual $i$ to each of the $k(j)$ questions which relate to the $j=1, \ldots, J=9$ variables of interest. Multiple questions are sampled for each individual and variable, which is then defined as the composite information extracted from all those questions.

Each of these questions is designed to share a common underlying scale, such that coherent respondents will have similar Likert scores across all the questions relating to a given variable. Therefore, by design, we assume low intrarespondent, intra-variable volatility of the underlying probability of each possible response to those related questions. We do not assume equal answers; just equal, or sufficiently similar, latent probabilities driving those answers to equivalent-scale questions.

In order to define a composite of these questions into a variable, there are multiple possible routes. For example, we could map these Likert-scale responses to a binary scale, and then simply map the sum to a binomial. This approach would, however, ignore the finer picture provided by the multi-category scale sampled.

An unconstrained multinomial ordered approach, while coherent at the population level with potentially multimodal populations, would fail to provide coherence between the probabilities at the individual level, an issue outlined in [82]. For example, a population's composite Likert distribution of a variable can be multimodal, with half of the population likely to provide very high values to a question and the other half likely to provide low values to that question. This multimodality, however, cannot exist at the individual level. An individual's coherent answer to any question should not encompass a high probability on both a low and a high value of the Likert response to a question. In fact, the probabilities should be monotonic on either side of the modal scale value.

A restricted multinomial ordered approach, such as that detailed in [82] is possible, with the implication of a much larger parameter space to estimate, but would require imposing bounds on the thresholds dividing the latent space that are not dissimilar from a more parsimonious Binomial assumption, such as the described in [81], in order to ensure monotonicity. Additionally, each individual may interpret the scales in a different, subjective way, so assuming a common set of thresholds in the ordered scale across individuals would also seem arbitrary for our application. We discard this approach also on the basis of the parametric burden induced for lower samples, which would hinder the usefulness of our model for Emerging Market analysis.

Alternatives that use Poisson or Gaussian densities, though numerically and theoretically appealing, would fail to provide the bounded parameter space in which the data is defined.

Finally, a mixed binomial approach [81] would be possible, but there is not enough justification or expected gains from increasing the complexity of the model, as this author admits, against the simpler binomial approach. Our approach is more parsimonious in the parameter space dimensionality implied by our distributional assumptions (with the evident trade-off for estimation). See [81]-[83] for more details.

We choose to build the model on a set of coherent rules at the individual level, and from there induce a populationbased distribution. For this purpose, we adopt a two-stage approach for [82] defining the variables:

- Step 1: In order to impose monotonicity on both sides of the mode, and since the shape of the distribution at the intra-respondent level is unknown, following [81] we assume a Binomial probability mass function for the responses, so that $Q_{i, k @} \sim \operatorname{Bin}\left(P_{i, k @ m}, n_{k q}\right.$. The advantage of this approach is the direct interpretability of $\mathrm{E}\left(\mathrm{Q}_{\mathrm{i}, \mathrm{k} D}\right)=\mathrm{n}_{\mathrm{i}, \mathrm{k} Q} P_{\mathrm{i}, \mathrm{k}(\mathrm{j})}$ as the expected value of the Likert-scale for each individual. Additionally, it ensures the coherence needed from an individually-driven monotonic set of preferences on either side of the mode: $P\left(Q_{i, k \emptyset}=x\right)<P\left(Q_{i, k \emptyset}=y\right)$ if $x<y<\operatorname{mode}\left(Q_{i, k \emptyset}\right.$, or, $x \geqslant y>\operatorname{mode}\left(Q_{i, k \emptyset}\right)$.

- $\quad$ Step 2: We are interested in modelling $Y_{i, j}=\sum_{j=1}^{k @ Q} Q_{i, k}$. We chose the sum as the sufficient statistic. Note that a factor decomposition of the question responses would be equivalent by construction to our approach, since the questions are assumed, by construction, to contain equivalent information. $Y_{i, j}$ can be shown to follow a Poisson-Binomial distribution for any arbitrary set $\left[\mathrm{P}_{\mathrm{i}, \mathrm{kp}}\right]$. However, as seen in, this density can itself be safely approximated as a Binomial distribution, for cases where, at the individual level, the responses come from Binomial densities with similar $\mathrm{P}_{\mathrm{i}, \mathrm{kQ}}$. Since, as aforementioned, the questions are built such that, for coherent respondents, $P_{\mathrm{i}, \mathrm{k} \emptyset}$ are similar for each individual $\tilde{i}$ across all its responses $\mathrm{k}(\mathrm{j})$ to the multiple questions composing that variable, then $Y_{i, j} \sim \operatorname{Bin}\left(P_{i, j} n_{j}\right)$, where $P_{i, j}$ is the unknown average probability for each of those questions, and $n_{j}=\sum_{j=1}^{k} n_{k[j]}$. In fact, it can be shown from that this approximation allows for the location to be estimated correctly, while the scale error is always positive (introducing additional uncertainty in the model, rather than artificially compressing the density). This scale 
error will have known bounds, ranging from $2 \%$ (for central values of $\mathrm{P}_{\mathrm{i}, \mathrm{kg}}$, to $11 \%$ for extreme values of $\mathrm{P}_{\mathrm{i}, \mathrm{k} \emptyset}$, for cases with a wide $10 \%$ range between the different $\mathrm{P}_{\mathrm{i}, \mathrm{k} \emptyset}$ relating to a given question $\mathrm{j}$.

As described in [81], our proposed model will be built on the assumption of $n_{k p}-1$ independent and identically distributed binary mini-trials embedded in the responses to each question for each of the Likert categories. The probability of each of those mini-trials will define the subject's preferences. We are not claiming that the probabilities of responding in a given category to each question are the same between individuals, nor are we claiming that the probabilities are similar between variables for a given individual. We just assume that, for a given individual and for a given variable, those unknown probabilities driving his responses must be coherent for similar questions relating to that variable, even if the actual responses are different. 


\section{APPENDIX B-1: Model Description}

Let $\left[Y_{i, j}, n_{j}\right]$ be a set of observable pairs, corresponding to each of the $j=1_{n} \ldots, J$ variables sampled, and each of the $\tilde{I}=1 \ldots N$ individuals interviewed. Each of these pairs is composed by (1) an observed variable, which corresponds to the sum of observed responses to each of the questions in the survey, and (2) the maximum possible number of counts that this sum of observed responses can take (known at the time of survey design).

Each $Y_{i, j}$ is assumed to be an independent realization of a binomial distribution with unknown probability $P_{i, j}$, which is both variable-specific and individual-specific. Therefore, there are $\mathrm{J} \times \mathrm{N}$ such unknown probabilities in our model. These probabilities are mapped, through a logistic link $\mathrm{L}$, to latent variables $\mathrm{U}_{\mathrm{i}, \mathrm{j}}$, also unknown, which follow the specification driven by the proposed model approach in this paper.

Our model will assume two sources of error added to the graphical model design: (1) Observational error: The responses that each individual give and/or the recording of those by the surveyor may not express the true underlying beliefs of those individuals. This error is embedded in the binomial probability mass function; (2) Model error: Although we propose a graphical model that relates the underlying variables, we are cognescent that every model is subject to misspecification. Thus we incorporate a Gaussian error term $\epsilon_{j}$ in the model equations, which is built in the Bayesian context as the prior uncertainty about the latent coefficients $U$. Therefore the precision term $\tau$ represents the degree of model misspecification in this approach. The larger this precision term results, the smaller our misspecification. These errors are assumed to be independent for each latent variable, a reasonable assumption for this application, although this assumption can be easily relaxed through the addition of a secondary hierarchy in the precision.

The latent variables $U$ relate to each other according to the model specifications, rather than the observed $Y_{i, j}$ which are observed only with error. Additionally, each of these latent variables $U_{i, j}$ has a potentially nonzero average for the population parameter $a_{j}$, and each individual departs from that average on the basis of the value of the other latent factors that have a linear impact parameter $\beta_{\mathrm{j}, \mathrm{k}}$, as well as a source of misspecification in the model.

Regarding the choices for the hyper parameters, which are specified below, the misspecification error precision parameter, $\mathrm{T}$ is assumed a priori to have a reasonably large mean of 1 and flat density (the posterior mean resulted in a much larger value, implying a much smaller misspecification). $\left\{a_{j}\right\}$ a priori are assumed to be centered around zero, though the posterior confirms clear departures from this prior representation indicating population biases. Similarly the $\left[\beta_{\mathrm{j}, \mathrm{k}}\right]$ parameters are assumed to be centered around zero, equivalent to assuming the non-existence of the link between the latent variables $[\mathbf{j}, \mathbf{k}]$, so that the data must be the driver to provide any evidence of existence of those links. The prior densities were chosen based on conjugacy criteria. Other hyper parameter values were tested, with no evidence of any difference in the conclusions or numerical estimates from the posterior distributions. The model can be expressed in its conditional form as:

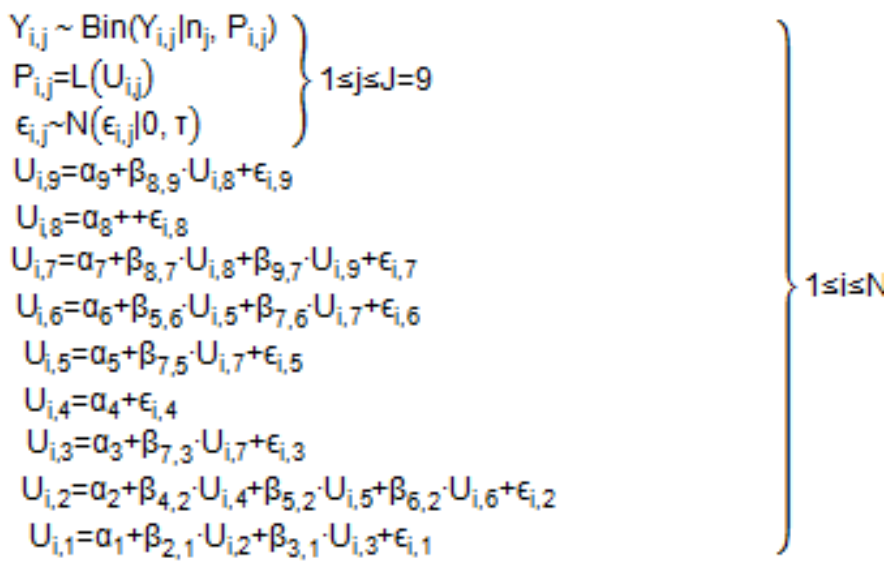

$$
\left.\begin{array}{l}
\beta_{\mathrm{j}, \mathrm{k}} \sim \mathrm{N}\left(\beta_{\mathrm{j}, \mathrm{k}} \mid 0,0.25\right) \mathrm{j} \neq \mathrm{k} \\
\mathrm{a}_{\mathrm{j}} \sim \mathrm{N}(\mathrm{a} \mid \mathrm{j}, 0,1 \mathrm{e}-6) \\
\mathrm{T} \sim \mathrm{Ga}(\mathrm{T} \mid 0.001,0.001)
\end{array}\right\} 1 \leq \mathrm{j}, \mathrm{k} \leq \mathrm{J}=\mathrm{G}
$$

